\title{
ANALISIS KEUNTUNGAN USAHATANI KELAPA DI KECAMATAN PADANGSIDIMPUAN BATUNADUA
}

\author{
Faisal Rahman Dongoran \\ Program Studi Ilmu Ekonomi, Program Pascasarjana, Universitas Negeri Medan, \\ Sumatera Utara, Indonesia \\ Email: fairahdo@gmail.com
}

\begin{abstract}
As a traditional crop, coconut is a versatile plant (tree of life) and has an economic value that is good enough to be developed particularly in the context of community economic development. This study aims to determine the effect of input variables $X 1$ (Wide Land), X2 (Labor Costs), and X3 (Cost Fertilizer) against the benefits of coconut farm in the district Padangsidimpuan Batunadua. Analytical model used is the CobbDouglas profit function with the help of Eviews v5.1 application.The results showed that simultaneous variables $X 1, X 2$, and $X 3$ affect the benefits of coconut farm with Fstat is 1728,765 . partially each variable as: $X 1$ shows a positive and significant impact on profits by ilai tcount 53.811 and Prob. Of 0.000., X2 showed positive and significant influence on profits by the value of 21.503 tcount and Prob. Of 0.000., and X3 shows a negative influence to the value of -2.511 tcount and Prob. Of 0.0138 . Furthermore, from the obtained values for the regression coefficient of $0.9834 \times 1$ means any addition of land area per ha will increase the gain of 0.9864 rupiah per $\mathrm{Ha}$ X2 of 0.9757 means that any additional labor costs / yields would increase the profit of 0.9575 rupiah and -0.0651 for $X 3$ which means every addition 1 rupiah of fertilizer costs will reduce profits 0,0651 rupiah. From the analysis it can be concluded, that the coconut farm production and profits in Kecataman Padangsidimpuan Batunadua still can be improved by optimizing the use of variable inputs of fertilizer and land.
\end{abstract}

Keywords: coconut, benefits, land, labor, fertilizer.

\section{PENDAHULUAN}

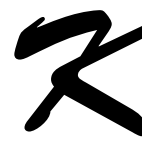

elapa merupakan salah satu komoditi perkebunan yang penting bagi Indonesia disamping kakao, kopi, lada, dan vanili. Komoditi ini telah lama dikenal dan sangat berperan bagi kehidupan bangsa Indonesia baik ditinjau dari aspek ekonomi maupun aspek sosial budaya.

Kota Padangsidimpuan merupakan salah satu kota sedang berkembang yang terletak di Provinsi Sumatera Utara dengan luas wilayah 14.684.680 Ha dan jumlah penduduk 188.499 jiwa dan memiliki 6 kecamatan sebagai pusat pertumbuhan ekonominya yang 
antara lain; Kecamatan Padangsidimpuan Tenggara, Kecamatan Padangsidimpuan Selatan, Kecamatan Padangsidimpuan Batunadua, Kecamatan Padangsidimpuan Hutaimbaru, Kecamatan Padangsidimpuan Utara, dan Kecamatan Padangsidimpuan Angkola Julu (BPS Kota Padangsidimpuan, 2010).

Di wilayah kota Padangsidimpuan, tanaman kelapa merupakan komoditas kedua setelah tanaman karet yang memilki luas area tanaman perkebunan rakyat terbesar yaitu seluas 502 ha, dan kecamatan yang memiliki luas areal tanaman kelapa perkebunan rakyat terluas adalah Kecamatan Padangsidimpuan Batunadua yaitu 340 Ha.

Tabel 1. Luas Tanaman Perkebunan Rakyat di Kota Padangsidimpuanmenurut Jenis Tanaman 2007 - 2009 (Ha)

\begin{tabular}{clccc}
\hline No & Jenis Tanaman & $\mathbf{2 0 0 7}$ & $\mathbf{2 0 0 8}$ & $\mathbf{2 0 0 9}$ \\
\hline 1 & Karet & 2.128 & 2.066 & 2.066 \\
2 & Kelapa Sawit & 5 & 45 & 45 \\
3 & Kopi & 243 & 141 & 141 \\
4 & Kelapa & $\mathbf{1 . 2 8 5}$ & $\mathbf{5 0 2}$ & $\mathbf{5 0 2}$ \\
5 & Coklat & 250 & 150 & 150 \\
6 & Cengkeh & 11 & 2 & 2 \\
7 & Kulit Manis & 55 & 76 & 65 \\
8 & Kemiri & 49 & 90 & 90 \\
9 & Pinang & 36 & 48 & 45 \\
\hline
\end{tabular}

Sumber: Dinas Pertanian Kota Padangsidimpuan

BPS Kota Padangsidimpuan (2010) juga memaparkan, bahwa luas tanaman kelapa perkebunan rakyat di wilayah Kota Padangsidimpuan tahun 2007-2009 mengalami penyusutan yang sangat tajam. Hanya dalam kurun waktu satu tahun saja, luas area tanaman kelapa di wilayah tersebut susut hingga kurang $50 \%$ dari total luas area sebelumnya yaitu $1.285 \mathrm{Ha}$ menjadi $502 \mathrm{Ha}$ (Tabel 1).

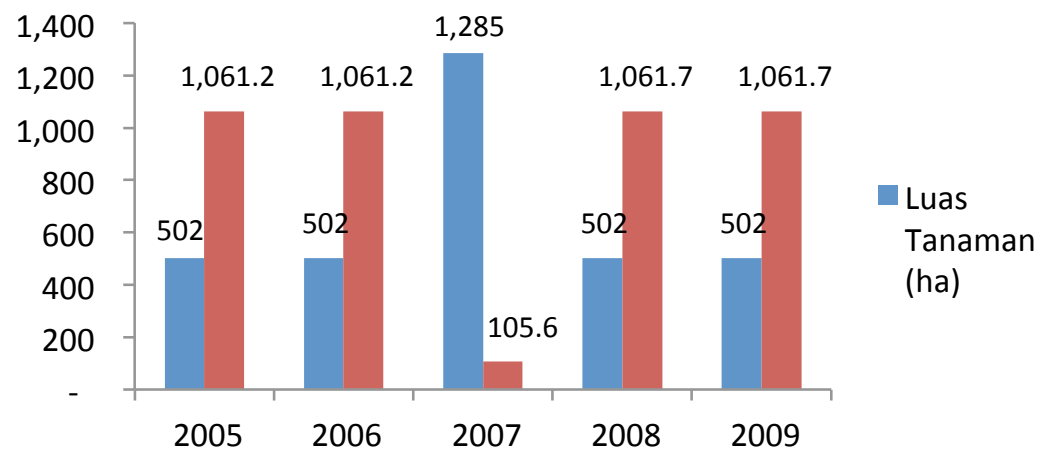

Sumber: BPS Padangsidimpuan (2010)

Gambar 1. Luas Tanaman dan Produksi Kelapa Tanaman Perkebunan Rakyatdi Kota Padangsidimpuan Tahun 2005-2009 
Thn

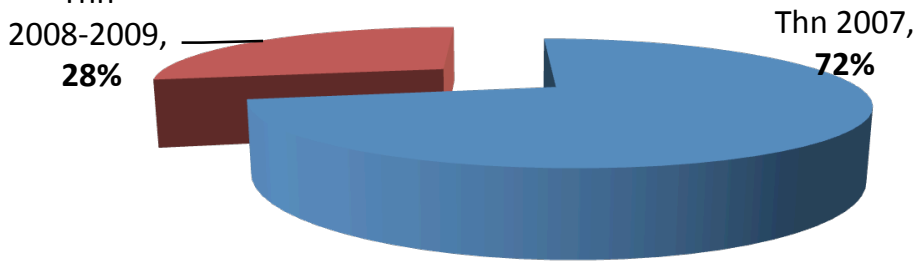

Sumber: BPS Padangsidimpuan (2010).

Gambar 2.Kondisi Luas Tanaman Perkebunan Kelapa Rakyatdi Kota Padangsidimpuan Tahun 2007-2009

Kecamatan Padangsidimpuan Batunadua selain memiliki area tanaman kelapa yang terluas, juga merupakan Kecamatan yang memiliki kontribusi produksi kelapa terbesar dibanging Kecamatan lainnya dengan kemampuan menghasilkan kelapa diatas ratarata yaitu sebesar 2,9 ton/ha/tahun. Artinya, komoditas kelapa didaerah ini berproduksi dengan baik dan menjadi sumber pendapatan yang dapat diandalkan oleh masyarakat setempat. . Untuk jelasnya dapat dilihat pada gambar berikut ini.

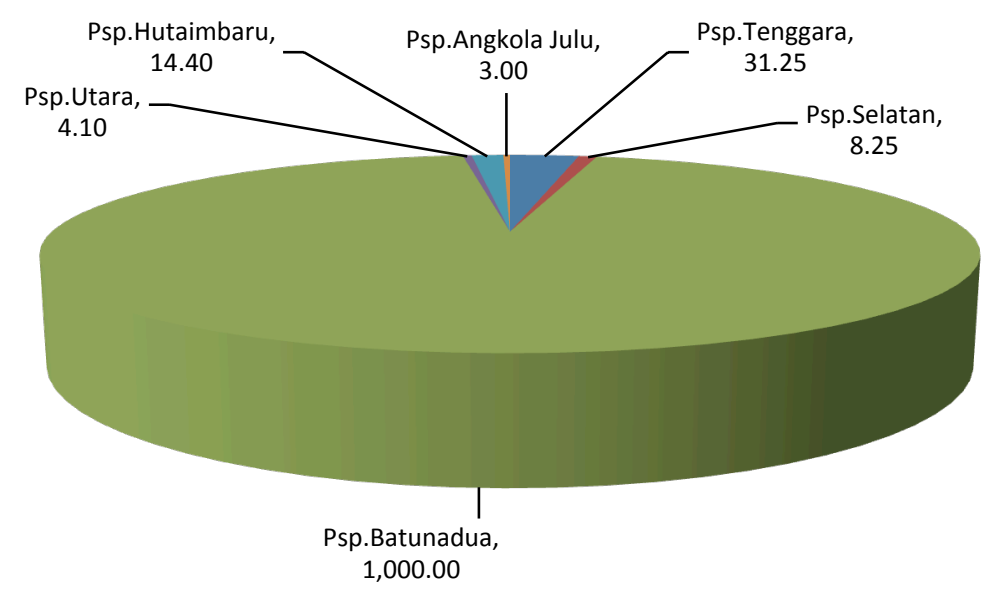

Sumber: BPS Padangsidimpuan (2010)

Gambar 3.Kontribusi Produksi Kelapa Tanaman Perkebunan RakyatMenurut Kecamatan di Kota Padangsidimpuan Tahun 2009

Adanya perbedaan luas areal tanam dan produktivitas yang menyolok antara kecamatan Padangsidimpuan Batunadua dengan kecamatan lainnya mencerminkan bahwa komoditas kelapa yang diusahakan petani dibeberapa kecamatan dengan luas lahan yang berbeda adalah sesuai dengan agroklimat daerahnya. Karenanya, daerah kecamatan Padangsidimpuan Batunadua memiliki potensi yang cukup baik, unggul, serta strategis, dan menguntungkan untuk dikembangkan dalam upaya menunjang pertumbuhan perekonomian kerakyatan melalui sektor perkebunan (kelapa). 
Kondisi perkebunan kelapa di Kecamatan Padangsidimpuan ini sesuai dengan yang diutarakan oleh Supadi dan Sumanaf (2006), bahwa dalam perekonomian Indonesia, kelapa merupakan salah satu komoditas strategis karena perannya yang besar bagi masyarakat sebagai sumber pendapatan, sumber utama minyak dalam negeri, sumber devisa, sumber bahan baku industri (pangan, bangunan, farmasi, oleokimia), dan sebagai penyedia lapangan kerja.

Hal senada juga diungkapkan oleh Sarmidi (2009), bahwa tanaman kelapa juga merupakan tanaman serbaguna yang mempunyai nilai ekonomi tinggi. Seluruh bagian pohon kelapa dapat dimanfaatkan untuk kepentingan manusia. Hampir seluruh bagian pohon, dari akar, batang, daun sampai buahnya dapat digunakan untuk kebutuhan kehidupan manusia sehari-hari. Daun yang masih muda digunakan sebagai bungkus ketupat, hiasan, ataupun bahan baku obat tradisional. Daun yang tua dianyam dan digunakan sebagai atap. Lidinya digunakan untuk membuat sapu. Batang kelapa digunakan sebagai bahan baku perobatan, mebel dan bahan bangunan. Akar kelapa digunakan sebagai bahan baku bir atau zat warna.

Sejak dahulu usahatani kelapa di wilayah Kecamatan Padangsidimpuan Batunadua dilakukan secara tradisional dengan input sarana produksi yang sangat minim atau bahkan tidak sama sekali yang tidak terlepas dari keterbatasan modal, ditambah keyakinan yang berlaku dikalangan masyarakat bahwa usahatani ini tidak memerlukan pemupukan, sehingga berdampak pada rendahnya produktifitas dan tingkat keuntungan yang diperoleh petani kelapa.

Disisi lain, dengan rendahnya penghasilan yang diperoleh dari kelapa menyebabkan petani tidak memiliki modal untuk memelihara kebun secara intensif, apalagi menggarap lahan perkebunan secara optimal maupun mengolah hasil (Supadi dan Nurmanaf, 2006).

Untuk meningkatkan produktivitas kelapa dari setiap lahan, petani dihadapkan pada suatu masalah penggunaan modal dan teknologi yang tepat. Dalam menghadapi pilihan tersebut kombinasi penggunaan modal seperti benih, pupuk dan obat-obatan disamping tenaga kerja yang tepat akan menjadi dasar dalam melaksanakan pilihan tersebut.

Pilihan terhadap kombinasi penggunaan tenaga kerja, benih, pupuk, obat-obatan yang optimal, diharapkan akan mendapatkan hasil yang maksimal. Dengan kata lain suatu kombinasi input dapat menciptakan sejumlah produksi dengan cara yang lebih efesien (Soekartawi, 2002). Namun dalam kenyataannya, masalah penggunaan faktor produksi yang terdapat pada usahatani masalah utama yang selalu dihadapi petani disamping faktor produksi juga masalah keahlian. Seperti diketahui bahwa pendapatan mempunyai hubungan langsung dengan hasil produksi usahatani, sedangkan produksi yang dihasilkan ditentukan oleh keahlian seseorang dalam mengelola penggunaan faktor produksi yang mendukung usahatani seperti tanah, tenaga kerja, modal dan manejemen. 
Kecamatan Padangsidimpuan Batunadua dilihat dari aspek ekologis merupakan daerah yang potensial untuk pengembangan usahatani kelapa, hal ini dapat dicermati dari data statistik yang sajikan oleh Dinas Pertanian dan BPS Kota Padangsidimpuan, bahwa produksi tanaman kelapa mencapai 1.000 ton pada tahun 2008 (2,9 ton/ha/tahun).

Namun disisi yang lain, dalam pengembangannya petani kelapa menghadapi permasalahan yaitu produktivitas yang mengalami stagnasi pada tahun 2009 (2,9 ton/ha/tahun), harga faktor produksi (bibit, tenaga kerja, pupuk dan pestisida) setiap tahun hampir dipastikan naik dan harga kelapa berfluktuasi, serta faktor pengembangan produktivitas turunan kelapa yang belum dikelola dengan baik.

Rumusan masalah dalam penelitian ini adalah: Apakah terdapat pengaruh luas lahan, biaya tenaga kerja, biaya pupuk terhadap keuntungan usahatani kelapa pada di Kecamatan Padangsidimuan Batunadua?

\section{MODEL PENELITIAN}

Kelapa juga disebut pohon kehidupan, karena semua bagian dari pohon kelapa dapat dimanfaatkan untuk kehidupan manusia, seperti batang, daun, bunga, buah. Dari buah kelapa dapat diambil sabut, tempurung, air dan daging buah. Daging buahnya pun dapat menjadi bahan baku produk lain, seperti kopra, minyak goreng, santan, kelapa paut kering, dan lain-lain (Sarmidi, 2009). Suatu usahatani dikatakan efektif apabila petani atau produsen dapat mengalokasikan sumber daya yang mereka miliki (yang dikuasai) sebaik-baiknya; dan dikatakan efesiensi apabila pemanfaatan sumber daya tersebut menghasilkan keluaran (output) yang melebihi masukan (input) (Soekartawi, 1995).

Miller dan Minner (1999:250) menyatakan, bahwa produksi merupakan konsep arus. Apa yang dimaksud dengan konsep arus (flow concept) disini adalah dimana produksi merupakan kegiatan yang diukur sebagai tingkat-tingkat output per unit periode/waktu. Sedangkan outputnya sendiri, senantiasa diasumsikan konstan kualitasnya. Maka, bila berbicara tentang peningkatan produksi, berarti peningkatan output dengan mengasumsikan faktor-faktor lain yang sekiranya berpengaruh tidak berubah sama sekali.

Faktor produksi adalah semua korbanan yang diberikan pada tanaman agar tanaman tersebut mampu tumbuh dan menghasilkan dengan baik. Faktor produksi dikenal pula dengan istilah input, production factor dan korbanan produksi. Faktor produksi memang sangat menentukan besar kecilnya produksi yang diperoleh. Untuk menghasilkan suatu produk, diperlukan pengetahuan hubungan antara faktor produksi (input) dan produksi (output). Hubungan antara input dan output ini disebut dengan fungsi produksi atau "factor of relationship" (Sitanggang, 2005).

Perubahan sistem pengusahaan pertanian yang tradisional ke semi tradisional atau ke komersial membawa dampak terhadap keputusan petani yang didasarkan konsep 
utilitas (utility maximization) ke konsep atas dasar keuntungan (profit maximization) (Soekartawi, 2002)

Keuntungan dapat diperoleh dengan cara membandingkan pendapatan total (TR) dan biaya total (TC). Pendapatan total adalah sama dengan jumlah unit output yang terjual (Y) dilakukan harga output per unit, maka:

$$
\pi=\mathrm{TR}-\mathrm{TC}
$$

Dimana :

$\begin{array}{ll}\Pi & =\text { keuntungan (Profit) } \\ \text { TR } & =\text { pendapatan total (Total Revenue) } \\ \text { TC } & =\text { biaya total (Total Cost) }\end{array}$

Biaya total yang dikeluarkan perusahaan adalah biaya yang dibutuhkan untuk memproduksi output $\mathrm{Y}$, yaitu sebesar jumlah faktor input yang digunakan Xi dikalikan dengan harga faktor input sebesar Wi. Dengan demikian keuntungan dapat dirumuskan :

$$
\pi=p \cdot Q-W_{1} X_{1}, \ldots W_{n} X_{n}
$$

Dimana :

$$
\begin{array}{ll}
\Pi & =\text { keuntungan } \\
\mathrm{P} & =\text { harga } \\
\mathrm{Q} & =\text { produksi } \\
\mathrm{W} & =\text { biaya } \\
\mathrm{X} & =\text { variable input/tetap }
\end{array}
$$

Dimana output $(Y)$ merupakan fungsi produksi $f\left(X_{i}, \ldots X_{n}\right)$, sehingga rumus keuntungan lebih lanjut dapat dituliskan :

$$
\pi=p \cdot f\left(X i, \ldots . X_{n}\right)-W_{i} \cdot X_{i}, \ldots W_{n} \cdot X_{n}
$$

Dimana :

$$
\begin{array}{ll}
\Pi & =\text { keuntungan } \\
\mathrm{p} & =\text { harga } \\
\mathrm{W} & =\text { biaya } \\
\mathrm{X}_{\mathrm{i}, . . \mathrm{n}} & =\text { variable input/tetap }
\end{array}
$$

Keberhasilan usahatani kelapa dipengaruhi oleh faktor internal maupun faktor eksternal. Faktor internal berupa tingkat harga input variabel, tingkat harga input tetap, jumlah produksi, kualitas produksi kelapa serta perilaku petani dalam mengalokasikan input-input maupun penanganan pasca panen,dan faktor eksternal berupa tingkat harga yang diterima petani, jumlah pembelian hasil oleh pasar dan kebijakan pemerintah. Disisi lain, usahatani kelapa adalah kegiatan untuk memproduksi yang pada akhirnya akan dinilai dari biaya yang dikeluarkan dan penerimaan yang diperoleh. Oleh karena itu, untuk lebih meningkatkan usahatani kelapa yang diperlukan adalah bagaimana mengalokasikan faktor-faktor produksi usahatani pada lahan agar lebih efisien. Secara skematis, kerangka pemikiran penelitian ini digambarkan sebagai berikut: 


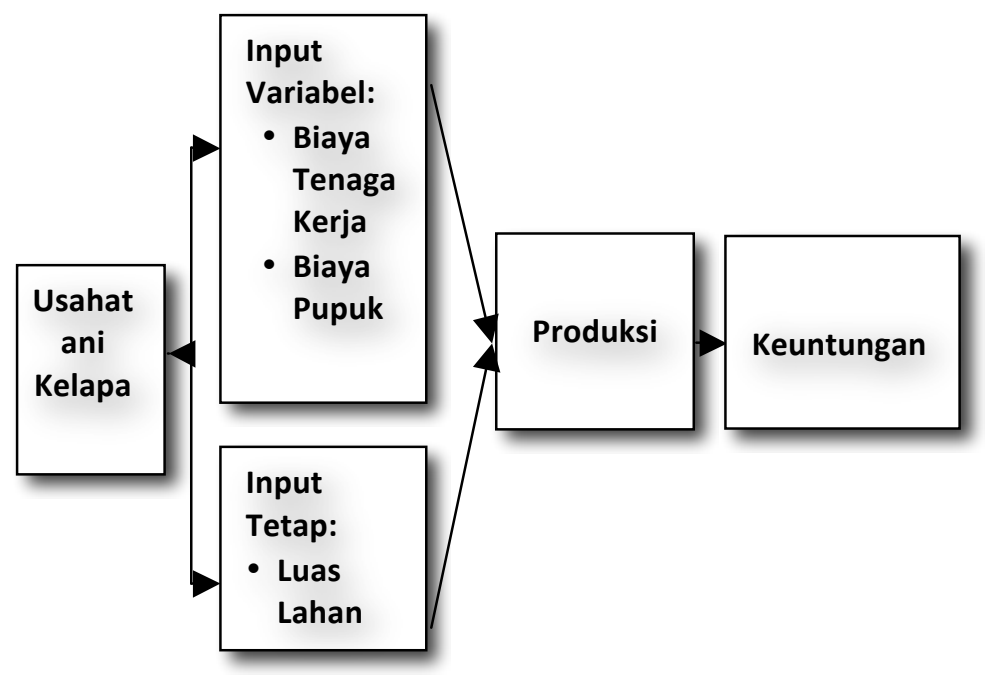

Gambar 5.Kerangka berpikir faktor-faktor yangmempengaruhi keuntungan usahatahi kelapa

Penelitian ini menggunakan model fungsi keuntungan Cobb-Douglas yang diderivasi dari fungsi produksi Cobb-Douglas.Menurut Yotopoulos dan Lau (1976) bentuk fungsi keuntungan yang diturunkan dari persamaan fungsi produksi Cobb-Douglas yang dalam bentuk logaritma natural persamaan yang digunakan dalam model dapat dituliskan sebagai berikut :

$$
\begin{aligned}
& \ln \pi^{*}=A^{*} \sum \alpha i^{a i^{*}} \ln x i^{*} \sum \beta j^{*} \ln Z j \\
& \ln \pi^{*}=\ln A^{*}+\alpha_{1}{ }^{*} \ln x_{1}+\alpha_{2}{ }^{*} \ln x_{2}+\beta_{1}{ }^{*} \ln z_{1}+e_{0}
\end{aligned}
$$

Keterangan:

$\pi^{*} \quad=$ keuntungan yang telah dinormalkan dengan harga kelapa

$\mathrm{A}^{*} \quad=$ intersep

$\mathrm{X}_{1}{ }^{*} \quad=$ biaya upah kerja yang telah dinormalkan dengan harga kelapa

$\mathrm{X}_{2}{ }^{*} \quad=$ biaya pupuk yang telah dinormalkan dengan harga kelapa

$\mathrm{Z}_{1} \quad$ = input tetap luas lahan

ai* $\quad=$ parameter input variable yang diduga, $\mathrm{i}=1$ dan 2

$\beta j^{*} \quad=$ parameter output tetap yang diduga, $\mathrm{j}=1$

\section{HASIL DAN PEMBAHASAN}

Model regresi linear berganda dalam penelitian ini menganalisis pengaruh faktorfaktor produksi terhadap keuntungan usahatani kelapa dengan variabel dependen ( $\mathrm{Y}$ ) yaitu variabel keuntungan dan variabel independen $(X)$ yaitu luas lahan, tenaga kerja dan pupuk. 
Tabel 2. Estimasi Hipotesis Luas Lahan, Biaya Tenaga Kerja, dan Biaya Pupuk Terhadap Keuntungan Usahatani Kelapa di Kecamatan Padangsidimpuan Batunadua

\begin{tabular}{|c|c|c|c|c|}
\hline Variable & Coefficient & Std. Error & t-Statistic & Prob. \\
\hline C & 0.827707 & 0.301679 & 2.743665 & 0.0074 \\
\hline LOG_LL & 0.983364 & 0.018274 & 53.81139 & 0.0000 \\
\hline LOG_BTK & 0.957522 & 0.044529 & 21.50310 & 0.0000 \\
\hline LOG_HP & -0.065128 & 0.025928 & -2.511887 & 0.0138 \\
\hline R-squared & \multicolumn{3}{|c|}{0.983315 Mean dependent var } & 6.562642 \\
\hline Adjusted R-squared & \multicolumn{3}{|c|}{0.982747 S.D. dependent var } & 0.292514 \\
\hline S.E. of regression & \multicolumn{3}{|c|}{0.038422 Akaike info criterion } & -3.637845 \\
\hline Sum squared resid & \multicolumn{3}{|c|}{0.129913 Schwarz criterion } & -3.528202 \\
\hline Log likelihood & \multicolumn{3}{|c|}{171.3408 F-statistic } & 1728.765 \\
\hline Durbin-Watson stat & \multicolumn{3}{|c|}{ 2.287953 Prob(F-statistic) } & 0.000000 \\
\hline
\end{tabular}

Sumber: Data Penelitian Diolah

Berdasarkan tabel estimasi hipotesis diatas diperoleh persamanaan sebagai berikut:

$$
Y=0.827707+0.983364 \text { Log_LL + 0.957522 Log_BTK - 0.065128Log_HP }
$$

\section{Interpretasi Pengaruh Luas Lahan Terhadap Keuntungan Usahatani Kelapah $\left(X_{1}\right)$}

Berdasarkan hasil perhitungan bahwa $X_{1}$ (1uas lahan) berpengaruh positif terhadap keuntungan usahatani kelapa. Pengaruh luas areal yang positif terhadap besarnya keuntungan yang diterima petani dapat diketahui dari nilai koefisien regresi sebesar 0,9834.Artinya, semakin luas areal usahatani kelapa yang diusakan maka semakin besar keuntunganyang diterima dengan kata lain apabila luas lahan ditambah $1 \mathrm{Ha}$, maka keuntungan usahatani kelapa akan meningkat sebesar $0,9834 \mathrm{~kg} / \mathrm{ha}$ dengan asumsi ceteris paribus (faktor-faktor lain dianggap konstan).

\section{Interpretasi Pengaruh Biaya Tenaga Kerja Terhadap Keuntungan Usahatani Kelapa} $\left(X_{2}\right)$

Berdasarkan hasil perhitungan bahwa variabel $\mathrm{X}_{2}$ (biaya tenaga kerja)berpengaruh positif dan signifikan terhadap keuntungan usahatani kelapa sebesar 0,9575 , artinya semakin tinggi biaya tenaga kerja/panenyang dikeluarkan, maka semakin besar keuntungan yang diterima, dengan kata lain apabila biaya tenaga kerja di tambah Rp. 1, maka keuntungan usahatani kelapa akan meningkat sebesar Rp. 0,9575 dengan asumsi ceteris paribus (faktor-faktor lain dianggap konstan).

\section{Interpretasi Pengaruh Biaya Pupuk Terhadap Keuntugan Usahatani Kelapa $\left(X_{3}\right)$}

Berdasarkan hasil perhitungan bahwa variabel $X_{3}$ (biaya pupuk)berpengaruh negatif terhadap keuntungan usahatani kelapa sebesar -0.0651 . Artinya semakin tinggi biaya pupuk maka akan mengurangi keuntungan usahatani kelapa, dengan kata lain biaya 
pupuk ditambah Rp 1, maka keuntungan usahatani kelapa akan berkurang sebesar Rp. 0.0651 dengan asumsi ceteris paribus (faktor-faktor lain dianggap konstan).

\section{PEMBAHASAN UJI EKONOMETRIKA}

a. Uji Multikolinearitas

Dari nilai matriks korelasi antar variabel diketahui bahwa tidak terdapat variabel yang memiliki nilai VIF yang lebih besar dari 10, maka dapat disimpulkan bahwa tidak terjadi gejala multikolinearity

b. Uji Normalitas

Pengujian terhadap uji normalitas dengan diperoleh hasil nilai Jacque Berra (JB) yang seluruhnya lebih kecil dari nilai Chi-Square pada $\alpha=5 \%$, atau jika nilai probabilitasnya seluruhnya lebih besar dari 0,05. Artinya, Ho tidak ditolak berarti terjadi penyimpangan asumsi normalitas atau pengganggu/residual terdistribusi secara normal.

c. Heteroskedastisitas

Uji Heteroskedastisitas dilakukan dengan menggunakan uji White. Uji tersebut meregresikan nilasi residual kuadrat dari model regresi terhadap variable-variabel indepedennya. Kiriteria yang digunakan adalah jika nilai probabilitas $O b s{ }^{*} R$ Square yang dihasilkan lebih besar dari 5 persen, maka dapat dikatakan tidak adanya heteroskedastisitas dalam model regresi ini. Adapun hasil uji heteroskedastisitas

Tabel 1.3. Hasil Uji White

\begin{tabular}{l|l|l}
\hline Nilai Obs ${ }^{*} \boldsymbol{R}$ Square & Probability & Kesimpulan \\
\hline 12.57 & 0.182 & Tidak Heteroskedastitas \\
\hline
\end{tabular}

Sumber: Data Penelitian

\section{KESIMPULAN DAN SARAN}

\section{KESIMPULAN.}

Berdasarkan hasil penelitian dapat disimpulkan sebagai berikut:

1. Secara simultan variable luas lahan, biaya tenaga kerja, dan biaya pupuk berpengaruh signifikan terhadap keuntungan usahatani kelapa.

2. Secara parsial (a) luas lahan berpengaruh positif dan signifikan terhadap keuntungan usahatani kelapa, (b) biaya tenaga kerja berpengaruh positif dan signifikan terhadap keuntungan usahatani kelapa, dan (c) Biaya pupuk berpengaruh negatif dan signifikan terhadap keuntungan usahatani kelapa.

3. Usahatani kelapa di Kecamatan Padangsidimpuan Batudanua Kota Padangsidimpuan belum dikelola secara optimum, sebab penggunaan faktor produksi lainnya seperti bibit unggul, pestisida, dan lain-lain belum digunakan dalam usahatani kelapa. 
4. Usahatani kelapa di Kecamatan Padangsidimpuan Batunadua memiliki peluang ekonomi yang sangat baik untuk dikembangkan dalam upaya peningkatan ekonomi kerakyatan di wilayah Kota Padangsidimpuan.

\section{SARAN}

Berdasarkan hasil penelitian diatas, maka penulis memberikan saran-saran sebagai berikut:

1. Untuk meningkatkan keuntungan usahatani kelapa di Kecamatan Padangsidimpuan Batunadua, maka diperlukan peningkatan biaya tenaga kerja, pengetahuan teknik budidaya/bercocok tanam kelapa, bantuan pendanaan (kredit) oleh pemerintah setempat melalui Koprasi Unit Desa (KUD).

2. Pemerintah diharapkan dapat memfasilitasi masyarakat pertani kelapa dalam peningkatan pengetahuan dan wawasan dalam teknik pengelolaan dan pengolahan produk turunan kelapa, sehingga produk komoditas kelapa tidak hanya berfokus pada buah saja.

3. Kepada para petani agar lebih intensif dalam hal pengelolaan usahatani kelapa mulai dari pembibitan, penanaman, pemeliharan/perawatan, dan panen.

4. Kepada peneliti selanjutnya, diharapkan mengidentifikasi variable-variabel lainnya yang dapat mempengaruhi keuntungan usahatani kelapa, seperti penggunaan teknologi dibidang pertanian lainnya.

\section{DAFTAR PUSTAKA}

Badan Pusat Statistik Kota Padangsidimpuan. 2010. Padangsidimpuan Dalam Angka 2010. Padangsidimpuan, Sumatera Utara: Badan Pusat Statistik Kota Padangsidimpuan. hal 115-145.

Lau and Yotopoulos. 1976.Profit Supply and Demand Functions. American Journal Agro Economic. 54: p. 11-18.

Miller, R.L.R.E. Miener, 1999. Teori EkonomiMikro Intermediate. Raja Grafindo Persada. Jakarta.

Sarmidi, Amin. 2009, Cocopreneurship, Aneka Peluang Bisnnis dari Kelapa, Edisi I, Andi, Yogyakarta.

Sitangang, Paula JH., 2005. Analisis Efisiensi Ekonomi Penggunaan Faktor-Faktor Produksi Pada Usahatani Stroberi Di Kabupaten Karanganyar. Skripsi Fakultas Pertanian. Universitas Sebelas Maret. Hal; 25.

Soekartawi, 1995. Analisis Usahatani. UI-Press. Jakarta.

Soekartawi, 2002. Prinsip Dasar Ekonomi Pertanian. Teori dan Aplikasi. Edisi Revisi 2002. PT. Raja Grafindo Persada. Jakarta.

Supadi dan Nurmanaf AR., 2006. Pemberdayaan Petani Kelapa Dalam Upaya Peningkatan Pendapatan. Jurnal Litbang Pertanian. 2006; hal 26.

QE Journal Vol.01-No.04-10 